\title{
Desempenho de reator integrado de lodo ativado com biofilme em leito móvel
}

\section{Integrated fixed film activated sludge reactor performance}

\section{Fábio Yugo Fujii}

Engenheiro civil e mestre em Engenharia Hidráulica e Ambiental pela Escola Politécnica da Universidade de São Paulo (USP) - São Paulo (SP), Brasil; Engenheiro da empresa JNS - Engenharia, Consultoria e Gerenciamento Ltda - São Paulo (SP), Brasil.

\section{Roque Passos Piveli}

Professor associado do Departamento de Engenharia Sanitária e Ambiental da

Escola Politécnica da USP - São Paulo (SP), Brasil.

\section{Fábio Campos}

Biólogo, doutorando em Saúde Pública na Faculdade de Saúde Pública da USP - São Paulo (SP), Brasil.

\section{Rodrigo Freitas Bueno}

Biólogo, doutorando em Engenharia Hidráulica e Ambiental na Escola Politécnica da USP - São Paulo (SP), Brasil.

\section{Pedro Alem Sobrinho}

Professor titular do Departamento de Engenharia Hidráulica e Ambiental da Escola Politécnica da USP - São Paulo (SP), Brasil.

\section{Resumo}

O objetivo deste estudo foi avaliar os efeitos da presença de suportes plásticos móveis (carriers) no processo de lodo ativado por meio da operação, sob diferentes tempos de retenção de sólidos para remoção de matéria carbonácea e nitrogênio, de dois sistemas aeróbios. Um deles, denominado LAC, foi constituído por reatores de lodo ativado com biomassa apenas em suspensão, e comparado com outro, LAl, com reatores integrados de lodo ativado com biofilme em leito móvel. Monitorou-se o crescimento das biomassas em suspensão e aderida e as condições ambientais nos reatores. Testes respirométricos determinaram os coeficientes cinéticos relativos à nitrificação. Foi possível a aplicação de carga de aproximadamente duas vezes a que foi suportada por um sistema de lodo ativado, a nitrificação se estendeu até reduzidas idades do lodo aeróbio e a desnitrificação ocorreu eficientemente. As velocidades específicas de crescimento das bactérias nitritantes e nitratantes foram determinadas para o processo com biofilme aderido, resultando similares às obtidas apenas com biomassa em suspensão.

Palavras-chave: lodo ativado; remoção de nitrogênio; MBBR; IFAS

\begin{abstract}
The aim of this study was to evaluate the effects of plastic media carriers presence in the activated sludge process through the operation under different solids retention times, for the removal of carbonaceous organic matter and ammonia nitrogen, of two aerobic systems. One of them, called LAC, was constituted by activated sludge reactors with suspended biomass only and compared with another, LAI, with integrated fixed-film activated sludge reactors. The growth of attached and suspended biomass and environmental conditions in the reactors have been monitored. Respirometric analyzes were used to determine kinetic coefficients related to nitrification. It was possible to apply approximately twice the load supported by an activated sludge system, nitrification was extended until low solids retention times related to the aerobic and suspended biomass, and denitrification has occurred efficiently. The specific growth rate of nitrifying bacteria in attached biomass has resulted similar to that observed in suspended biomass.
\end{abstract}

Keywords: activated sludge; nitrogen removal; MBBR; IFAS.

Endereço para correspondência: Fábio Yugo Fujii - Rua Dr. Bittencourt Rodrigues, 112, apto. 93 - 01017-010 - São Paulo (SP), Brasil - E-mail: fujii@jnsecg.com.br Recebido: 05/06/12 - Aceito: 23/08/13 - Reg. ABES: 400 


\section{Introdução}

O processo de tratamento conhecido por Moving Bed Biofilm Reactors (MBBR) baseia-se no desenvolvimento de biofilme em leito móvel para a degradação de matéria orgânica e remoção de nutrientes do esgoto sanitário. Quando associado ao processo de lodo ativado, cultiva-se, ao mesmo tempo da biomassa aderida aos suportes plásticos, grande quantidade de biomassa em suspensão pelo artifício de recirculação de lodo, dotando o sistema de grande capacidade de carga. Nesta configuração híbrida, o processo é conhecido por Integrated Fixed Film Activated Sludge (Sistema integrado de lodo ativado com biofilme - IFAS) e constitui alternativa atraente para ampliação da capacidade nominal de uma estação de tratamento ou para prepará-la para a remoção de nitrogênio, sem aumento de volume de tanques reatores (LESSEL, 1993).

Biofilmes consistem em comunidades de micro-organismos desenvolvidas sobre superfícies. No caso em questão, os elementos de suporte são pequenas peças de polietileno, que apresentam extensa área superficial específica e se encontram suspensas e em movimento no lodo do reator. A agitação é proporcionada pelo próprio sistema de aeração, constituído por difusores de ar instalados no fundo do tanque (HEM, 1994).

As substâncias consideradas poluentes, matéria orgânica e nitrogênio na forma amoniacal, são o substrato para o crescimento da massa bacteriana cuja concentração, se apresentando na forma de biofilme, é muito maior que se estivesse em suspensão simplesmente. A atividade microbiológica é mais alta, fato devido à grande variedade de populações microbiológicas nos biofilmes (RUSTEN et al., 1995). Por esse motivo, a quantidade de substrato que pode ser removida por unidade de tempo é também maior.

Os biofilmes têm como característica importante a estabilidade a variações operacionais, sejam de carga, vazão, ou composição do esgoto afluente. Uma vez que as culturas estejam plenamente estabelecidas no meio suporte móvel, oferecem robustez ao sistema, resistindo a condições que o lodo em suspensão não seria capaz. Os níveis de nutrientes e de oxigênio dissolvido são as variáveis mais importantes de controle do sistema. A nitrificação também é beneficiada por esse efeito de estabilidade, na medida em que as bactérias nitrificantes também ficam instaladas nessas comunidades (ØDEGAARD et al., 1993).

Dependendo do objetivo do tratamento, podem ser instaladas câmaras anóxicas, com ou sem os elementos suporte, para obtenção da pré ou pós-desnitrificação. Rusten et al. (1995) desenvolveram pesquisa com MBBR em sistema com reatores em série, envolvendo pré-desnitrificação por meio de recirculação interna. O esgoto utilizado na pesquisa, desenvolvida na Noruega, era diluído e de baixa alcalinidade, recebendo apenas tratamento preliminar. A temperatura ambiente manteve-se entre 7 e $18,3^{\circ} \mathrm{C}$. Um dos resultados mais importantes foi a correlação entre a carga de nitrogênio amoniacal aplicada e a taxa de nitrificação, praticamente uma reta a $45^{\circ}$ para taxa de aplicação de amônia de 0 a $1,2 \mathrm{~g} \mathrm{~N}-\mathrm{NH}_{4} \cdot \mathrm{m}^{-2} \cdot \mathrm{d}^{-1}$ e velocidade de nitrificação entre 0 e 1,0 $\mathrm{gN}-\mathrm{NH}_{4} \cdot \mathrm{m}^{-2} \cdot \mathrm{d}^{-1}$.

Constatou-se também que taxas de aplicação de até $11 \mathrm{~g}$ DQO. $\mathrm{m}^{-2} \cdot \mathrm{d}^{-1}$ não interferiram na nitrificação, principalmente porque boa parte delas foi consumida na câmara anóxica.

Outra condição de suma importância para o desenvolvimento do processo MBBR é a concentração de oxigênio dissolvido a ser mantida nos tanques de aeração. Nos estudos desenvolvidos pelo mesmo grupo de pesquisadores noruegueses, principais responsáveis pela evolução dessa tecnologia, foi obtida a correlação entre taxa de nitrificação e concentração de oxigênio dissolvido. Inferiuse que a camada líquida estagnada junto à superfície do biofilme formado nos suportes móveis é limitante para a transferência de oxigênio. Como o oxigênio dissolvido é consumido para degradação de matéria orgânica por micro-organismos heterotróficos, que se posicionam na parte externa do biofilme, para obtenção da nitrificação sua concentração deve ser elevada para que haja penetração nas camadas internas, região em que predominam as bactérias nitrificantes. Concluíram que sob concentrações de oxigênio dissolvido abaixo de $2,5 \mathrm{mg} \cdot \mathrm{L}^{-1}$ a nitrificação praticamente cessa. Isto, se confirmado para regiões de temperaturas mais elevadas, representa um custo adicional para a aeração conveniente do sistema, já que o processo de lodo ativado opera normalmente com OD abaixo de 2,0 mg. $\mathrm{L}^{-1}$. Outro entrave econômico associado ao processo é o custo dos suportes plásticos móveis, na medida em que, dependendo dos valores praticados, a construção de novos tanques pode resultar mais econômica do que a conversão do sistema, fazendo com que o aprimoramento de estações de lodo ativado com esta tecnologia resulte atrativo apenas quando não se dispõe de área complementar para a ampliação da ETE ou em regiões em que o terreno é bastante valorizado.

Por meio de uma análise comparativa entre dois sistemas de lodo ativado, com características idênticas, operados em paralelo, foram identificados os efeitos da introdução desses elementos de suporte no reator de apenas um deles, com enfoque nas remoções simultâneas de nitrogênio amoniacal e matéria orgânica carbonácea, e nas condições dos parâmetros de processo necessárias para a sua ocorrência.

\section{Metodologia}

A pesquisa foi desenvolvida por meio de experimento em escala piloto no Centro Tecnológico de Hidráulica da Escola Politécnica da USP. Foram postos em marcha dois sistemas de lodo ativado de dimensões iguais, diferindo apenas pela introdução, em um deles, de suportes plásticos móveis para o desenvolvimento de biomassa aderida, ilustrado esquematicamente na Figura 1. Ao sistema convencional, que foi operado apenas com 


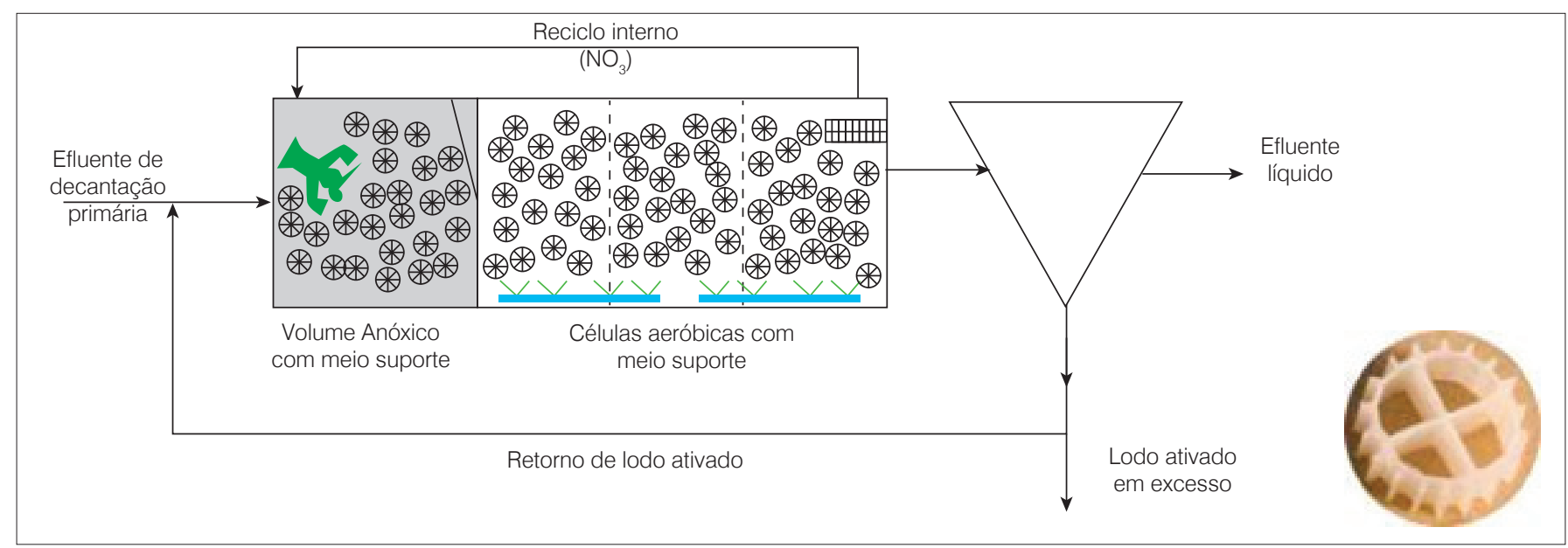

Figura 1 - Representação esquemática do sistema LAl, com suportes plásticos móveis e fotografia do modelo utilizado de suporte plástico.

biomassa em suspensão, foi dado o nome de LAC e o sistema, ou módulo, que recebeu a adição dos elementos de suporte, caracterizando um IFAS em leito móvel, recebeu a denominação de LAI.

O esgoto sanitário utilizado, proveniente do Conjunto Residencial da USP (CRUSP), recebeu tratamento prévio de peneiramento, desarenação, remoção de gordura e decantação primária.

Cada módulo de lodo ativado foi composto por um tanque em que foram constituídos os reatores biológicos, com volume útil de $800 \mathrm{~L}$, dividido por um septo em uma câmara anóxica de 270 L (1/3) contendo um misturador, e uma câmara aerada de 530 L (2/3) provida de difusores de bolha fina. A separação de sólidos foi feita no decantador secundário, portando raspador de parede e fundo. Além do retorno de lodo do decantador secundário para a entrada da câmara anóxica, cada sistema possuía bomba de recirculação interna da câmara aerada para a anóxica. O sistema piloto LAI, que representou o processo com reator biológico de leito móvel, recebeu suportes plásticos móveis do modelo K1, da AnoxKaldnes ${ }^{\circledR}$ (Veolia Water) tanto na câmara anóxica quanto na aerada. Estes elementos possuem área superficial específica estimada em $310 \mathrm{~m}^{2} \cdot \mathrm{m}^{-3}$ e ocuparam 50\% dos volumes úteis da câmara anóxica e da câmara aerada.

Segundo o delineamento experimental proposto, os dois sistemas operaram simultânea e paralelamente, procurando manter sempre a mesma relação alimento/micro-organismos A/M e a mesma idade do lodo, estabelecidas em relação apenas à biomassa em suspensão. Após a quantificação da biomassa aderida, no caso do sistema que operou com suportes plásticos móveis no tanque de aeração, foi possível correlacionar as condições operacionais com a quantidade total de biomassa suspensa mais aderida. A variação da idade do lodo se deu de forma a compor três fases experimentais, descritas na Tabela 1 .
Tabela 1 - Condições operacionais nos reatores, relativas à biomassa em suspensão.

\begin{tabular}{|ccccc} 
Fase & $\begin{array}{c}\text { Relação A/M } \\
\mathrm{kg} \mathrm{DBO} \text { Dg SSV }\end{array}$. $^{-1}$ & $\begin{array}{c}\text { Idade do Lodo } \\
\text { Heterotrófico (d) }\end{array}$ & $\begin{array}{c}\text { Idade do Lodo } \\
\text { Autotrófico (d) }\end{array}$ & $\begin{array}{c}\text { Duração } \\
\text { (d) }\end{array}$ \\
\hline 1 & 0,2 & 9,3 & 6,5 & 110 \\
\hline 2 & 0,3 & 6,2 & 4,3 & 70 \\
\hline 3 & 0,4 & 4,6 & 3,2 & 50 \\
\hline
\end{tabular}

Como pode ser observado, reduziu-se sucessivamente a idade do lodo, de forma a permitir a avaliação do crescimento relativo entre a biomassa heterotrófica suspensa e aderida em mais de uma condição operacional. Consequentemente, com a decorrente redução da idade do lodo autotrófico foram variadas as condições para a nitrificação, permitindo a comparação entre o comportamento do lodo ativado e do reator com suportes. A terceira fase teve a duração limitada pela interrupção da nitrifricação no sistema LAC.

Diariamente, eram procedidos os descartes de excesso de lodo, ajustadas todas as vazões de esgoto e lodo e a concentração de OD nos tanques de aeração (valores considerados: $1,5 \mathrm{mg} \cdot \mathrm{L}^{-1}$ no LAC, e 3,0 mg. $\mathrm{L}^{-1}$ no LAI). Eram medidos o pH e a temperatura por sensores instalados nos tanques de aeração.

O esgoto afluente às câmaras anóxicas e efluente de cada decantador secundário foi caracterizado duas vezes por semana, tendo-se determinado a Demanda Biológica de Oxigênio (DBO) (diluição e incubação a $20^{\circ} \mathrm{C}$ ), Demanda Química de Oxigênio (DQO) (método do refluxo aberto), NTK e N-Amoniacal (digestão, destilação e titulação), nitrito e nitrato (cromatografia iônica), alcalinidade total (titulação) e sólidos em suspensão totais e voláteis

Os lodos dos tanques de aeração e das linhas de retorno de lodo também foram analisados duas vezes por semana, determinando-se a concentração de sólidos em suspensão totais e voláteis 
(filtração em $1,2 \mu \mathrm{m}$, secagem em estufa a $104^{\circ} \mathrm{C}$ e calcinação em forno mufla a $550^{\circ} \mathrm{C}$ ). Foram realizados, também, exames de microscopia do lodo ativado e contagem de bactérias nitritantes e nitratantes.

A biomassa aderida aos suportes plásticos móveis foi quantificada por meio de coleta em tubos de Falcon de $40 \mathrm{~mL}$, raspagem das peças por meio de escova odontológica e quantificação de sólidos em suspensão voláteis (SSV), nitrogênio total kjeldahl (NTK) e fósforo total.

Foram realizados ensaios de respirometria visando a determinação das velocidades específicas máximas de crescimento das bactérias nitritantes e nitratantes $\left(\mu_{\mathrm{m}}\right)$, as constantes de meia saturação de Monod $\left(\mathrm{K}_{\mathrm{n}}\right)$ e as taxas máximas de utilização de amônia e nitrito $\left(\mathrm{r}_{\mathrm{n} \text { máx }}\right)$. Foram feitos testes com amostras dos tanques de aeração de ambos os sistemas, sendo que para o LAI houve ainda variação dos ensaios:

- Sem a presença dos suportes plásticos, avaliando somente a biomassa em suspensão;

- Com a presença dos suportes plásticos, avaliando a contribuição da biomassa aderida.

A determinação das taxas de consumo de oxigênio (TCO) foi feita mediante o uso de respirômetro marca Beluga, acoplado a sensor de OD marca Orion.

Foi empregado o modelo cinético de Marais e colaboradores, descrito em Haandel e Lubbe (2007). Equações utilizadas:

Concentração de nitrogênio necessário para a produção de lodo $\left(\mathrm{N}_{1}\right)$ :

$\mathrm{N}_{\mathrm{l}}=\mathrm{f}_{\mathrm{n}} \mathrm{X}_{\mathrm{v}} \mathrm{R}_{\mathrm{h}} / \mathrm{R}_{\mathrm{s}}$

em que: $\mathrm{f}_{\mathrm{n}}$ é a fração de nitrogênio no lodo biológico, $\mathrm{X}_{\mathrm{v}}$ é a concentração de sólidos em suspensão voláteis no tanque de aeração, $R_{h}$ é o tempo de retenção hidráulica e $\mathrm{R}_{\mathrm{s}}$ é a idade do lodo.

Concentração de nitrato formado $\left(\mathrm{N}_{\mathrm{c}}\right)$ :

$\mathrm{N}_{\mathrm{c}}=\mathrm{NTK}_{\mathrm{a}}-\mathrm{NTK}_{\mathrm{e}}-\mathrm{N}_{1}$,

em que NTK e NTK são as concentrações de NTK no afluente e efluente, respectivamente.

Concentração das bactérias autotróficas $\left(\mathrm{X}_{\mathrm{n}}\right)$ :

$\mathrm{X}_{\mathrm{n}}=\mathrm{Y}_{\mathrm{n}} \mathrm{R}_{\mathrm{s}} \mathrm{N}_{\mathrm{c}} /\left(1+\mathrm{b}_{\mathrm{n}} \mathrm{R}_{\mathrm{s}}\right) \mathrm{R}_{\mathrm{h}}$

em que $Y_{n}$ é o coeficiente de síntese celular e $b_{n}$ o coeficiente de decaimento endógeno das bactérias nitrificantes.
TCO máxima das bactérias nitritantes obtida por meio dos testes respirométricos:

$\mathrm{TCO}_{\text {n.máx }}=\mathrm{TCO}_{\text {exógena }}-\mathrm{TCO}_{\text {endógena }}$

Taxa máxima de nitritação ou nitratação $\left(\mathrm{r}_{\mathrm{n} \text {, máx }}\right)$ :

$\mathrm{r}_{\mathrm{n}, \text { máx }}=\mathrm{TCO}_{\mathrm{n}, \operatorname{máx}} / 4,57$

Velocidade específica máxima de crescimento:

$\mu_{\mathrm{m} 20}=\left(\mathrm{Y}_{\mathrm{n}} * \mathrm{r}_{\mathrm{n}, \max } / \mathrm{X}_{\mathrm{n}}\right)$

Constante de meia saturação de amônia e nitrito $\left(\mathrm{K}_{\mathrm{n}}\right)$ : Considerou-se que, quando a TCO começa a decrescer, o substrato (amônia ou nitrito) torna-se um fator limitante para o crescimento das bactérias nitrificantes. De acordo com a cinética de Monod, para estimar o valor da constante de meia saturação $\left(\mathrm{K}_{\mathrm{n}}\right)$ para nitritantes ou nitratantes, deve-se determinar a concentração de substrato no momento em que $\mu$ for $=1 / 2 \mu_{\text {máx }}$, ou que a $\mathrm{TCO}_{\mathrm{n}}=1 / 2 \mathrm{TCO}_{\mathrm{n} \text {.máx }}$. Esta determinação pode ser feita mediante o teste respirométrico. Por meio do respirograma determina-se a $\mathrm{TCO}_{\mathrm{n}}$ e, com os dados armazenados determina-se a área (A) que corresponde ao substrato residual em (mg O.L $\mathrm{L}^{-1}$ ), mediante a soma de trapézios. Calculam-se as concentrações de substrato amônia ou nitrito pela razão entre a área e o respectivo coeficiente estequiométrico de oxigênio por mol do substrato considerado $\left(K_{n}=A / 4,57\right.$ para amônia e $K_{n}=A / 1,14$ para nitrito).

\section{Resultados e Discussão}

\section{Comportamento dos processos de tratamento: matéria orgânica e nitrogênio}

Em relação à remoção de matéria orgânica, pode ser dito que os dois sistemas puderam ser mantidos sob operação estável e eficiente durante o período experimental. Em termos de DQO, observou-se que os efluentes se mantiveram relativamente estáveis, tendo ocorrido apenas alguns episódios de ligeira elevação ao longo de todo o período operacional (Figura 2). Observou-se baixa perda de sólidos junto com o efluente final, em ambos os processos e ao longo de toda a operação, ao mesmo tempo em que a DQO solúvel dos efluentes também permaneceu reduzida, demonstrando boa capacidade na digestão de matéria coloidal. Resultados semelhantes em um sistema MBBR foram obtidos por Minegatti et al. (2011)

Em relação à oxidação dos compostos nitrogenados, observou-se que enquanto o processo LAI se demonstrou eficiente e estável durante todas as fases experimentais, o sistema LAC apresentou-se instável durante boa parte da primeira etapa e ao final da terceira (Figura 3). 
De forma mais direta, pôde ser confirmada pelas séries históricas de concentração de nitrogênio amoniacal (Figura 4), a grande capacidade de nitrificação do reator do módulo LAI ao longo de todas as fases experimentais, de forma bastante estável, conferindo segurança e confiabilidade ao sistema de tratamento.

A diferença de comportamento entre os dois processos na primeira fase pode ser justificada pelo fato de que com idade do lodo de 9 dias, em relação apenas à biomassa em suspensão, a idade do lodo aeróbia, isto é, relativa apenas ao lodo do compartimento aerado do tanque, resulta em torno de 6 dias. Com as baixas temperaturas registradas no período, mínima de $14^{\circ} \mathrm{C}$ nos lodos dos tanques, a nitrificação não ocorreu satisfatoriamente no LAC. Já no LAI, a biomassa total disponível para a nitrificação, incluindo a parcela aderida, garantiu a manutenção de uma idade do lodo efetiva maior que 9 dias.

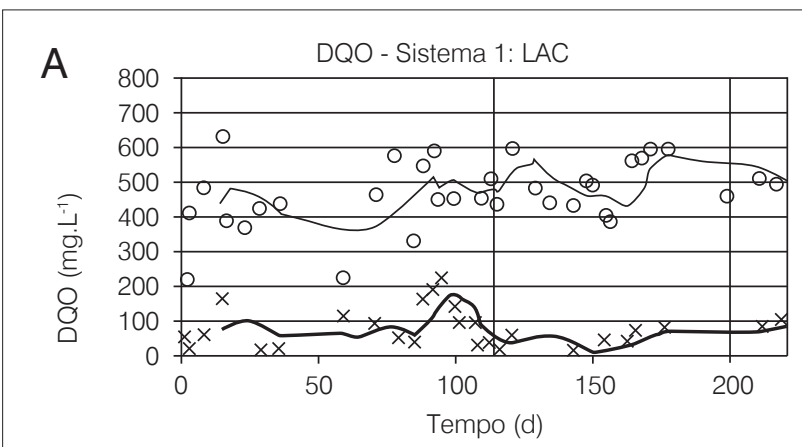

DQO: demanda química de oxigênio

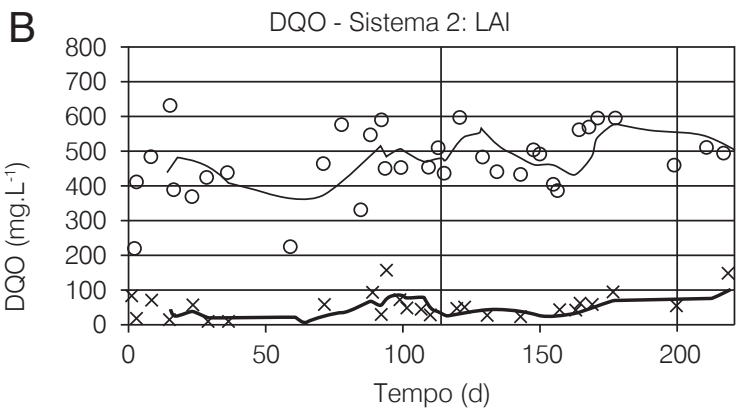

- Afluente $\times$ Efluente

- 4 por Média Móvel (Afluente) - 4 por Média Móvel (Afluente)

Figura 2 - Resultados de Demanda Química de Oxigênio-LAC (A) e LAI (B).

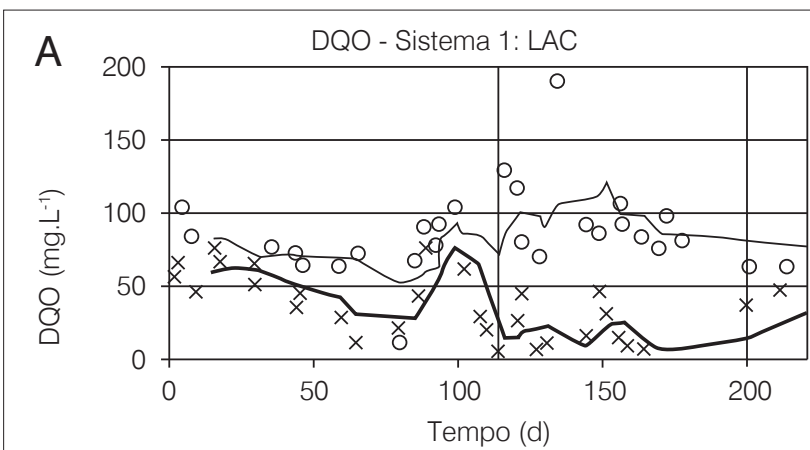

DQO: demanda química de oxigênio

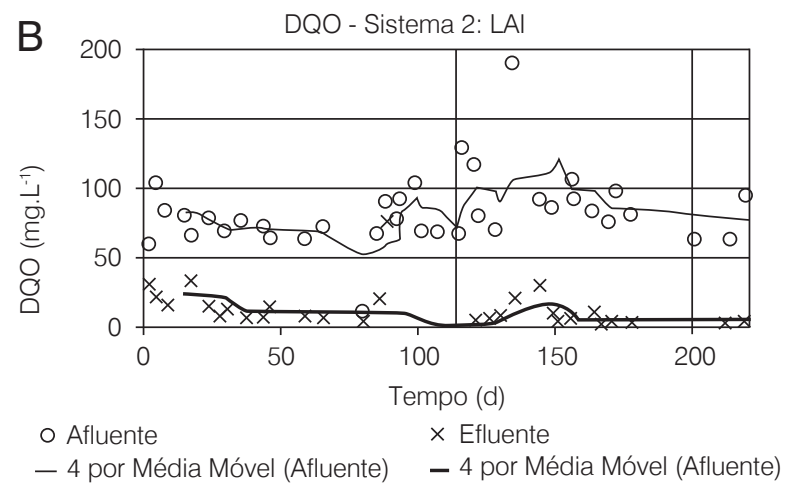

Figura 3 - Resultados de NTK-LAC (A) e LAI (B).

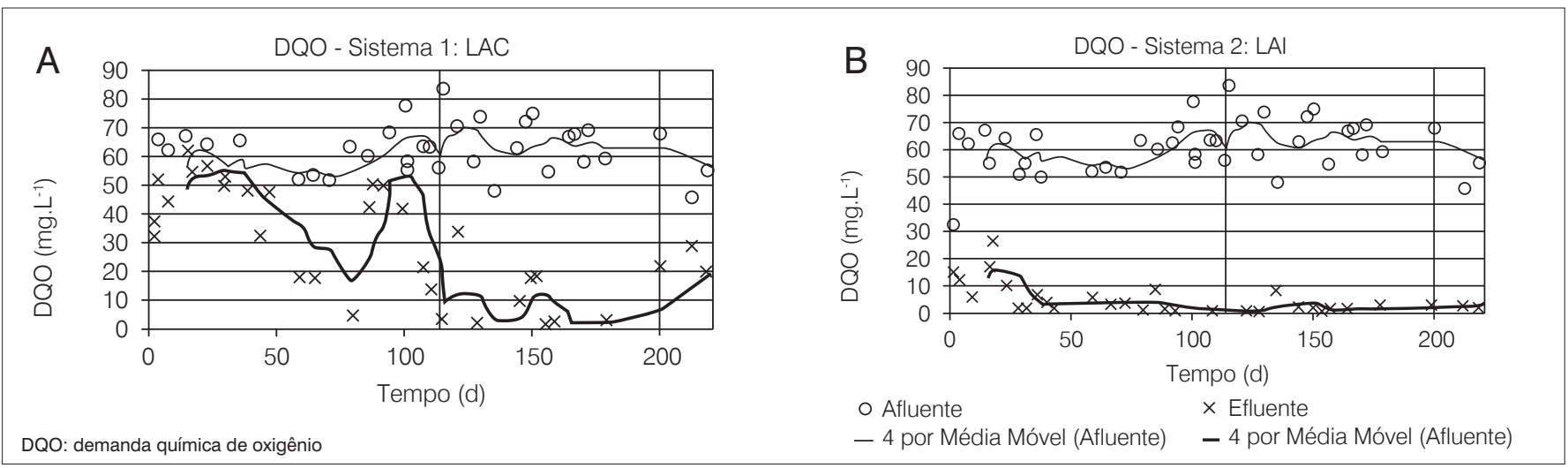

Figura 4 - Resultados de N-Amoniacal-LAC (A) e LAl (B). 
Durante a segunda fase, que se desenvolveu do $110^{\circ}$ até aproximadamente o $180^{\circ}$ dia, a nitrificação, desnitrificação e remoção de fósforo ocorreram de modo eficiente e estável no processo de lodo ativado. Isso foi relacionado com as altas temperaturas registradas durante esse período. Na terceira etapa, a baixa idade do lodo, considerando apenas a porção aeróbia, em torno de 3 dias, impossibilitou o crescimento das bactérias nitrificantes no LAC e a concentração de amônia no efluente elevou-se novamente. No sistema LAI, este processo permaneceu ocorrendo com alta eficiência em função da presença da biomassa aderida.

No processo com biofilme aderido, a remoção de nitrogênio ocorreu de forma eficiente durante todas as fases, apesar dos incrementos na relação alimento/micro-organismos e redução da idade do lodo (Figura 5). Efetivamente, toda a amônia oxidada para nitrato sofreu desnitrificação, a observar pelas baixas concentrações de nitrito e nitrato no efluente final. No caso do módulo LAC, além de menor eficiência na nitrificação, foram observadas concentrações das formas oxidadas de nitrogênio em curtos períodos no efluente final.

Este fato pôde ser mais bem observado na terceira fase, em que ocorreu um baixo nível de nitrificação no sistema de lodo ativado, com consequente acúmulo de nitrato.

\section{Caracterização das biomassas nos reatores}

Com relação à biomassa em suspensão nos reatores, observa-se que se procurou manter concentrações semelhantes de SSV nos reatores dos dois processos (Figura 6), de forma que a biomassa aderida possa constituir o diferencial. Observa-se também que as concentrações de SSV são decrescentes nos reatores à medida que se reduz a idade do lodo.

A biomassa aderida aos suportes também foi quantificada (Tabela 2). Embora até essa altura do estudo apenas quatro determinações tenham sido realizadas, em etapas posteriores da pesquisa foram realizadas diversas outras, sendo que a tendência de concentração de SST ligeiramente acima de $2.000 \mathrm{mg}$. $\mathrm{L}^{-1}$ e de SSV ligeiramente abaixo, foi mantida. Destes resultados resulta que, em média, $80 \%$ dos SST são voláteis, indicando lodo pouco mineralizado.

Com a redução progressiva da biomassa em suspensão ao longo das etapas experimentais, o acréscimo relativo à presença da biomassa aderida variou de 43 a $70 \%$, neste estudo em que os suportes plásticos ocuparam cerca de $50 \%$ do volume útil dos reatores.

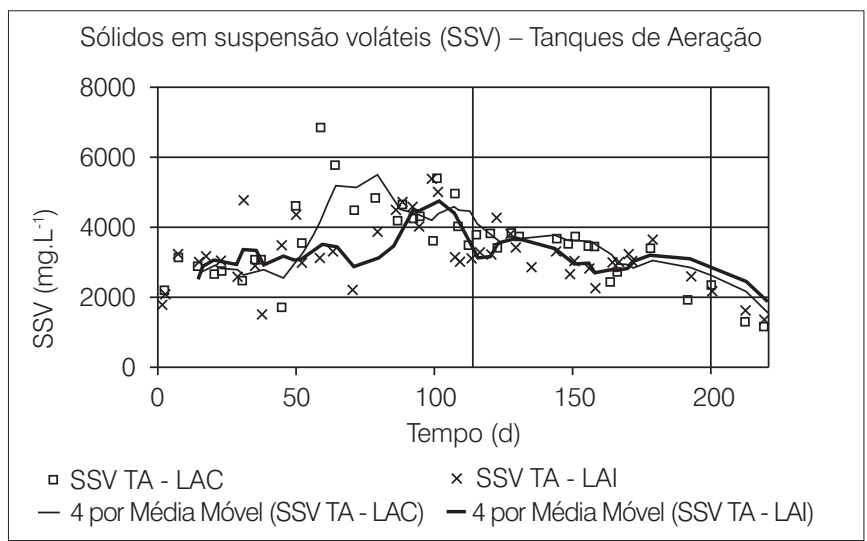

Figura 6 - Concentração de sólidos em suspensão voláteis nas biomassas em suspensão dos reatores.

Tabela 2 - Resultados da quantificação da biomassa aderida.

\begin{tabular}{lcccc} 
& \multicolumn{3}{c}{ SST } & \multicolumn{2}{c}{ SSV } \\
\cline { 2 - 5 } Data & $\mathrm{mg} \cdot \mathrm{L}^{-1}$ & $\mathrm{~g} \cdot \mathrm{m}^{-2}$ & $\mathrm{mg} \cdot \mathrm{L}^{-1}$ & $\mathrm{~g} \cdot \mathrm{m}^{-2}$ \\
\hline $02 / 09 / 2010$ & 2.088 & 13,92 & 1.698 & 11,32 \\
\hline $14 / 09 / 2010$ & 2.025 & 13,50 & 1.658 & 11,05 \\
\hline $28 / 09 / 2010$ & 2.182 & 14,54 & 1.793 & 11,95 \\
\hline $19 / 10 / 2010$ & 2.214 & 14,76 & 1.840 & 12,27 \\
\hline Média & 2.127 & 14,18 & 1.747 & 11,65 \\
\hline
\end{tabular}

SST: sólidos em suspensão totais; SSV: sólidos em suspensão voláteis

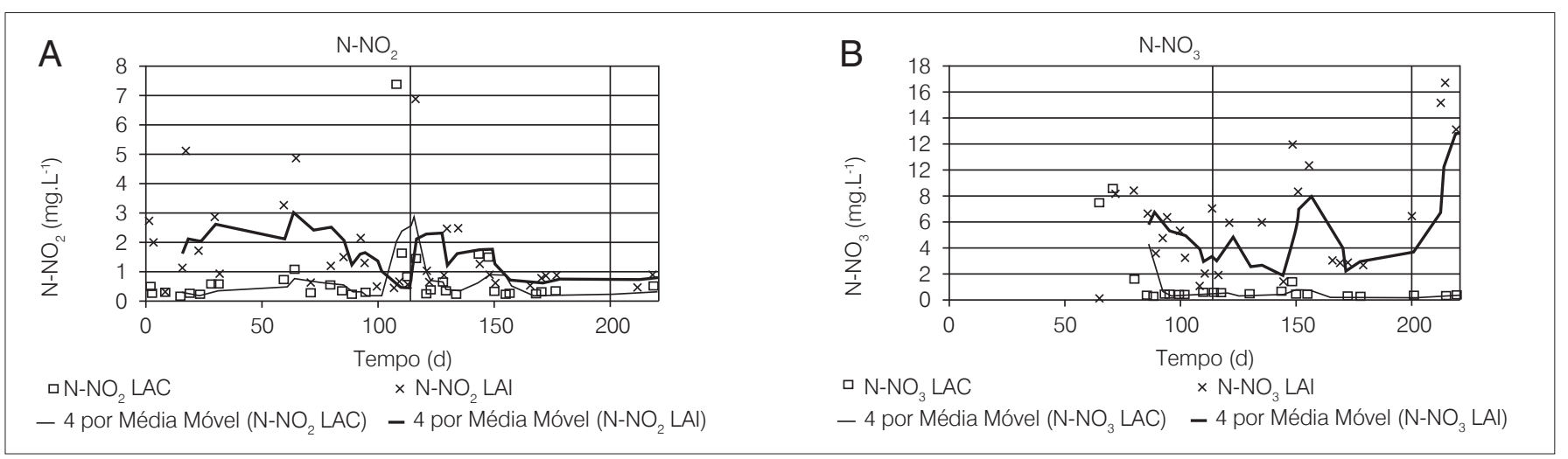

Figura 5 - Resultados de Nitrito (A) e Nitrato (B) - LAC e LAI. 


\section{Taxas de aplicação de Demanda Química de Oxigênio e amônia sobre a biomassa aderida e taxa de nitrificação}

Para estimativa das quantidades de substratos aplicadas à biomassa aderida, foram utilizados os valores orientativos das frações de remoção pelo biofilme recomendados por WEF (2009), com base em modelo cinético do processo.

Para a Fase 1, de idade do lodo aeróbia com referência à biomassa em suspensão de, aproximadamente, 6 dias, foi considerada a aplicação de $12,5 \%$ da DQO e 35\% do nitrogênio amoniacal para estimativa da contribuição do biofilme. Da mesma forma para a Fase 2, que operou com idade do lodo aeróbia de aproximadamente 4 dias, foram considerados 25\% de DQO e 50\% de amônia. Para a Fase 3, com idade do lodo aeróbia de aproximadamente 3 dias, foram considerados 37,5 e $65 \%$, na mesma ordem.

Na Figura 7 são apresentadas as taxas de aplicação de substrato, ou cargas aplicadas por área de biofilme. Os resultados das cargas orgânicas superficiais, calculadas de acordo com essa orientação, também são apresentados na forma de gráfico das séries históricas corrigidas dos valores de $\mathrm{DQO}$ e $\mathrm{NH}_{3}-\mathrm{N}$ para as frações de substrato destinadas à biomassa em suspensão.

Calculando as taxas de nitrificação e relacionando-as com a taxa de aplicação de amônia sobre o biofilme, obtém-se o gráfico da Figura 8, no qual pode ser observada alta eficiência em remoção nitrogênio amoniacal, mesmo sob altas taxas de aplicação superficial.

Pelos gráficos das Figuras 7 e 8 pode ser observado que as cargas chegaram aos limites das remoções obtidas por Hem et al. (1994), que obtiveram taxas de nitrificação de 0,7 a 1,2 g N.m ${ }^{2}$. $\mathrm{d}^{-1}$ para cargas de DBO de 1 a $2 \mathrm{~g} \cdot \mathrm{m}^{-2} \cdot \mathrm{d}^{-1}$ em um MBBR sem recirculação de lodo, a $15^{\circ} \mathrm{C}$ e com concentrações de oxigênio dissolvido no intervalo de 4 a 6 mg. $\mathrm{L}^{-1}$. Nesse estudo, para cargas de
DBO de 1 a 2 g.m $\mathrm{m}^{-2} \cdot \mathrm{d}^{-1}$ a taxa de nitrificação reduziu-se, cessando a nitrificação quando a carga de DBO ultrapassou a $5 \mathrm{~g} \cdot \mathrm{m}^{-2} \cdot \mathrm{d}^{-1}$. Como a nitrificação é muito dependente da temperatura, a operação do MBBR/IFAS no presente trabalho ocorreu em condições muito mais favoráveis do ponto de vista da cinética das reações.

De acordo com os resultados das análises de nitrogênio, a nitrificação ocorreu até a Fase 3, tendo perdido sua intensidade no final do período. Um dos fatores que contribuíram para essa queda de desempenho pode ter sido a alta solicitação em termos de aplicação superficial de substrato.

\section{Nitrogênio e fósforo na biomassa aderida}

Foram utilizadas oito amostras de lodo removido da superfície dos suportes para determinação dos teores de nitrogênio e fósforo. Relacionando-se os resultados com a massa de SSV presente nas respectivas amostras, foram encontradas as razões médias de 0,0728 g N-NTK/gSSV e 0,0074 g P-P/gSSV, valores inferiores aos normalmente obtidos em lodo ativado (biomassa em suspensão), quais sejam, 0,10 g N-NTK/gSSV e 0,022 g P-P $_{\mathrm{T}} / \mathrm{gSSV}$.

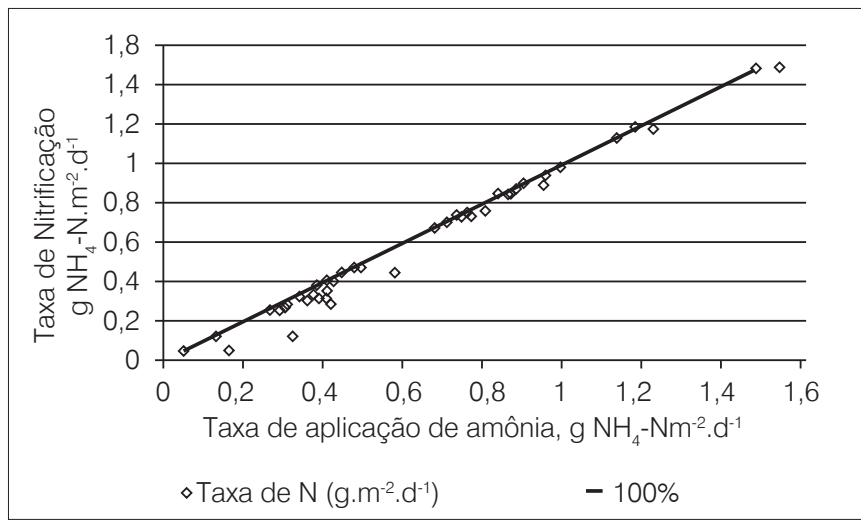

Figura 8 - Relação entre taxa de nitrificação e de aplicação de amônia sobre o biofilme.

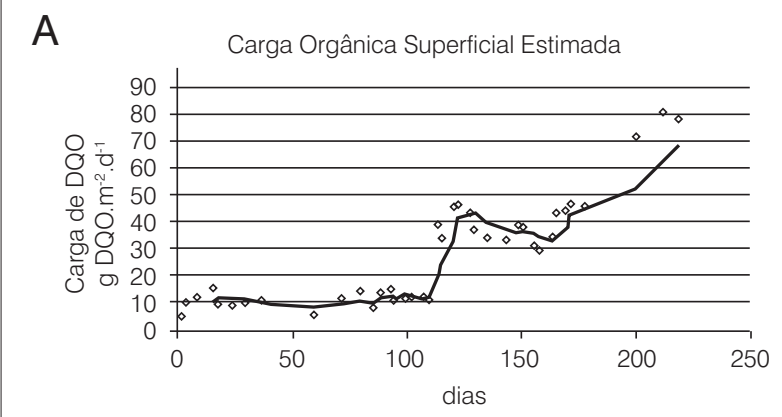

• Carga de DQO (g.m-2.d-1) — 4 por Média Móvel (Carga de DQO (g.m². d $\left.^{-1}\right)$ )
B

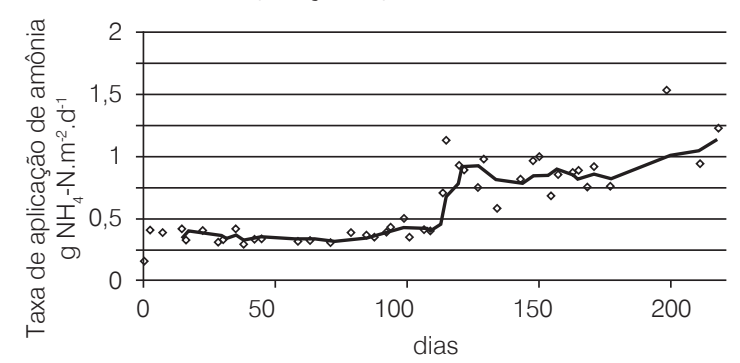

- Carga de $\mathrm{NH}_{3}\left(\mathrm{~g} \cdot \mathrm{m}^{-2} \cdot \mathrm{d}^{-1}\right) \quad$ - 4 por Média Móvel $\left(\right.$ Carga de $\left.\mathrm{NH}_{3}\left(\mathrm{~g} \cdot \mathrm{m}^{-2} \cdot \mathrm{d}^{-1}\right)\right)$

Figura 7 - Taxas de aplicação sobre o biofilme - Demanda Química de Oxigênio (A) e N-NH $(B)$. 


\section{Biomassa heterotrófica em suspensão e aderida no sistema LAl}

$\mathrm{Na}$ Tabela 3 são apresentados os resultados das contagens de micro-organismos presentes no lodo em suspensão e aderido aos suportes plásticos do sistema LAI.

Observou-se que tanto a biomassa em suspensão quanto a aderida encontravam-se em bom estágio da sucessão ecológica, apresentando densidades elevadas de protozoários, especialmente os livre-natantes, que indicam boa formação dos flocos biológicos, além da presença de alguns micrometazoários.

Com relação à microscopia do lodo ativado no LAC e da biomassa suspensa no LAI, não foram observadas diferenças em relação à diversidade biológica nos módulos experimentais. Entretanto, houve uma diferença significativa na quantidade de organismos por unidade de volume entre os módulos. No LAI, com a presença dos suportes móveis, disponibiliza-se suporte para desenvolvimento de microfauna aderida como ciliados pedunculados, favorecendo um melhor desempenho do sistema.

\section{Biomassa autotrófica em suspensão e aderida nos módulos LAC e LAI}

Na Tabela 4 são apresentados os resultados da contagem de bactérias nitritantes e nitratantes nos lodos em suspensão e na biomassa aderida.

Os resultados não podem ser considerados conclusivos. Ainda assim, demonstram consistência na medida em que o módulo LAC se encontrava com problemas na nitrificação na época em que esses ensaios foram realizados e as densidades de bactérias nitritantes e nitratantes resultaram significativamente menores em relação ao LAI. Neste, observou-se a contribuição bastante expressiva da biomassa aderida em termos de bactérias nitrificantes.

\section{Coeficientes cinéticos da nitrificação no sistema LAl}

Na ocasião da realização dos testes respirométricos, o módulo encontrava-se sob idade do lodo relativa à biomassa suspensa de 9 dias e tempo de retenção hidráulica de 0,4 dia. As demais condições são descritas na Tabela 5.

Foram adotados os seguintes coeficientes cinéticos, a $20^{\circ} \mathrm{C}: \mathrm{b}_{\mathrm{n}}=0,04 \mathrm{~d}^{-1}$, corrigido para a temperatura de estudo pelo fator $(1,04)^{(\mathrm{T}-20)}$ (MARAIS \&

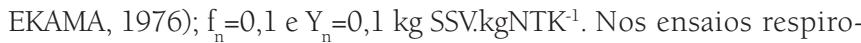
métricos, foram obtidas as taxas de consumo de oxigênio apresentadas na Tabela 6

Tabela 4 - Densidades de bactérias nitritantes e nitratantes nos lodos biológicos (NMP.g SSV-1).

\begin{tabular}{llccc} 
Data & Bactérias & $\begin{array}{c}\text { LAC } \\
(\text { NMP.g } \\
\text { SSV-1) }\end{array}$ & $\begin{array}{c}\left.\text { LAl (NMP.g SSV }{ }^{-1}\right) \\
\text { Biomassa } \\
\text { Suspensa }\end{array}$ & $\begin{array}{c}\text { Biomassa } \\
\text { Aderida }\end{array}$ \\
\hline $18 / 07 / 11$ & Nitritantes & $6,8.10^{3}$ & $7,7.10^{5}$ & $1,2.10^{6}$ \\
& Nitratantes & $3,4.10^{3}$ & $3,110^{6}$ & $6,6.10^{6}$ \\
\hline $01 / 08 / 11$ & Nitritantes & $8,4.10^{3}$ & $5,4.10^{6}$ & $5,5.10^{4}$ \\
& Nitratantes & $8,4.10^{2}$ & $5,5.10^{5}$ & $7,5.10^{5}$ \\
\hline $13 / 08 / 11$ & Nitritantes & $2,3.10^{4}$ & $2,2.10^{7}$ & $2,4.10^{5}$ \\
& Nitratantes & $1,1.10^{4}$ & $1,3.10^{5}$ & $1,4.10^{6}$ \\
\hline
\end{tabular}

SSV: sólidos em suspensão voláteis.

Tabela 5 - Condições operacionais do módulo LAl durante os testes respirométricos.

\begin{tabular}{lc} 
Variável & Resultado \\
$\mathrm{NTK}_{\mathrm{a}}\left(\mathrm{mgN} \cdot \mathrm{L}^{-1}\right)$ & 56 \\
$\mathrm{NTK}_{\mathrm{e}}\left(\mathrm{mgN} \cdot \mathrm{L}^{-1}\right)$ & 7,8 \\
$\mathrm{SSV}_{\text {b. suspensa }}\left(\mathrm{mg} \cdot \mathrm{L}^{-1}\right)$ & 2.385 \\
$\mathrm{SSV}_{\text {b. aderida }}\left(\mathrm{mg} \cdot \mathrm{L}^{-1}\right)$ & 2.270 \\
\hline
\end{tabular}

Tabela 6 - Resultados de taxas de consumo de oxigênio obtidos nos testes respirométricos.

\begin{tabular}{lcccc} 
Lodo ensaiado & Bactérias & $\mathrm{TCO}_{\text {endógena }}$ & $\mathrm{TCO}_{\text {exógena }}$ & $\mathrm{TCO}_{\text {máx }}$ \\
$\begin{array}{l}\text { Lodo suspenso }+ \\
\text { aderido do LAl }\end{array}$ & Nitritantes & 49 & 10 & 39 \\
$\begin{array}{l}\text { Lodo suspenso }+ \\
\text { aderido do LAl }\end{array}$ & Nitratantes & 38 & 23 & 15 \\
\hline
\end{tabular}

TCO: taxas de consumo de oxigênio

Tabela 3 - Biomassa heterotrófica em suspensão e aderida no sistema LAl.

\begin{tabular}{|c|c|c|c|c|c|c|c|c|c|c|c|c|}
\hline \multirow{3}{*}{ Data } & \multicolumn{6}{|c|}{ Protozoários (Org.g SSV ${ }^{-1}$ ) } & \multicolumn{6}{|c|}{ Metazoários (Org.g SSV-1) } \\
\hline & \multicolumn{2}{|c|}{ L-Natantes } & \multicolumn{2}{|c|}{ Pedunculados } & \multicolumn{2}{|c|}{ Pred. Flocos } & \multicolumn{2}{|c|}{ Rotíferos } & \multicolumn{2}{|c|}{ Mastigófaros } & \multicolumn{2}{|c|}{ Nematóides } \\
\hline & Susp & Ade & Susp & Ade & Susp & Ade & Susp & Ade & Susp & Ade & Susp & Ade \\
\hline $18 / 7 / 11$ & 383 & 900 & 311 & 600 & 61 & 6 & 383 & - & 8 & 47 & - & 12 \\
\hline $30 / 8 / 11$ & 822 & 355 & 6 & 587 & 17 & 23 & - & - & - & - & - & - \\
\hline $13 / 9 / 11$ & 4.932 & 265 & 97 & 90 & 252 & 84 & - & - & - & - & - & - \\
\hline
\end{tabular}

SSV: sólidos em suspensão voláteis; Susp: em suspensão; Ade: aderida; Pred. Flocos: predadores nos flocos. 
Na Tabela 7 são apresentados os resultados dos cálculos da velocidade específica máxima de crescimento de bactérias nitritantes e nitratantes.

Metcalf \& Eddy (2003) reportam valores de $\mu_{\mathrm{m} 20}$ na faixa de 0,2 a 0,9 $\mathrm{d}^{-1}$, enquanto que Marais e Ekama (1976) apresentam resultados na faixa de 0,33 a 0,65 $\mathrm{d}^{-1}$, ambos para biomassa em suspensão de lodos ativados em diferentes condições. Assim sendo, os resultados obtidos neste estudo podem ser considerados normais. Observou-se, também, no módulo LAI que a velocidade de nitratação resultou mais elevada que a de nitritação, demonstrando que a nitritação é a etapa mais limitante do processo.

$\mathrm{Na}$ Tabela 8 são mostrados os resultados da constante de meia saturação de amônia e nitrito do modelo de Monod.

Poduska e Andrews (1974), apud Haandel e Lubbe (2007), encontraram $\mathrm{k}_{\mathrm{n} 20}$ igual a $0,04 \mathrm{mg} \cdot \mathrm{L}^{-1}$, enquanto que Ekama e Marais (1976) obtiveram $1 \mathrm{mg} . \mathrm{L}^{-1}$ em seus estudos sobre cinética da nitrificação em lodo ativado, dentre tantos resultados apresentados na literatura nesta ampla faixa. Neste estudo, os resultados, de uma maneira geral, apresentam-se bastante próximos ao limite inferior.

Na Tabela 9 são mostrados os resultados da taxa máxima de utilização de amônia e nitrito.

Quando se comparam com os dados de literatura, os resultados de $r_{n \text {.máx }}$ obtidos no presente estudo podem ser considerados normais, refletindo o mesmo comportamento da velocidade específica de crescimento.

\section{Conclusões}

Dentre os aspectos mais importantes observados, destacam-se o desempenho superior alcançado pela tecnologia MBBR, em configuração IFAS, em termos de eficiência na remoção de matéria orgânica (91\% contra 85\% do sistema LAC) e nitrogênio (90\% contra 51\% do LAC), bem como a maior estabilidade operacional se comparado com o sistema de lodo ativado. Os resultados demonstram que é possível aumentar consideravelmente a capacidade de degradação de compostos orgânicos de um processo de lodo ativado quando se adicionam os elementos suporte. Em condição semelhante à avaliada, a adição de material de suporte em quantidade correspondente a uma fração de enchimento de 50\%, com área superficial específica de $300 \mathrm{~m}^{3} \cdot \mathrm{m}^{-2}$ pode, aproximadamente, duplicar a capacidade de um sistema de lodo ativado existente. A adição dos suportes móveis promoveu o desenvolvimento de biomassa aderida em quantidade da mesma ordem de grandeza de concentração da biomassa em suspensão. Esse aspecto, individualmente, não influencia proporcionalmente o desempenho do sistema, que está muito mais relacionado com a área superficial de biofilme como denominador mais apropriado
Tabela 7 - Velocidade específica máxima de crescimento de bactérias nitrificantes $\left(\mu_{m}\right)$.

\begin{tabular}{lcc}
\multirow{2}{*}{$\mu_{\mathrm{m} 20}\left(\mathrm{~d}^{-1}\right)$} & \multicolumn{2}{c}{ LAl } \\
& Biomassa suspensa + aderida \\
\cline { 2 - 3 } Média & Nitritantes & Nitratantes \\
\hline Máximo & 0,44 & 0,68 \\
\hline Mínimo & 0,55 & 0,75 \\
\hline Desvio Padrão & 0,12 & 0,42 \\
\hline Coeficiente de Variação (\%) & 0,22 & 0,17 \\
\hline Amplitude Total & 50,8 & 25,6 \\
\hline
\end{tabular}

Tabela 8 - Constante de meia saturação de amônia na equação de Monod para o crescimento das bactérias nitrificantes $\left(\mathrm{K}_{\mathrm{n}}\right)$.

\begin{tabular}{lcc} 
& \multicolumn{2}{c}{ LAI } \\
$\mathrm{K}_{\mathrm{n} 20}\left(\mathrm{mg} \cdot \mathrm{L}^{-1}\right)$ & Niomassa suspensa & + aderida \\
\cline { 2 - 3 } & Nitritantes & Nitratantes \\
\hline Média & 0,04 & 0,14 \\
\hline Máximo & 0,06 & 0,29 \\
\hline DP & 0,03 & 0,05 \\
\hline CV $(\%)$ & 0,02 & 0,12 \\
AT & 38,2 & 86,6 \\
\hline
\end{tabular}

Tabela 9 - Taxas máximas de utilização de amônia e nitrito $\left(r_{n \text { maxx }}\right)$.

\begin{tabular}{|c|c|c|}
\hline \multirow{2}{*}{$\begin{array}{l}r_{\text {n.máx }} \\
\text { Frações }\end{array}$} & \multicolumn{2}{|c|}{$\begin{array}{c}\text { LAI } \\
\text { Biomassa suspensa + aderida }\end{array}$} \\
\hline & Nitritantes & Nitratantes \\
\hline Média & 8,5 & 13,2 \\
\hline Máximo & 10,0 & 18,4 \\
\hline Mínimo & 5,5 & 8,6 \\
\hline DP & 2,29 & 4,90 \\
\hline CV (\%) & 27,0 & 37,1 \\
\hline AT & 4,5 & 9,8 \\
\hline
\end{tabular}

DP: desvio padrão; CV: coeficiente de variação; AT: amplitude total.

para a avaliação de taxas de aplicação de substratos. Os estudos da composição da biomassa aderida não revelaram aspectos que a diferenciem da biomassa em suspensão.

\section{Agradecimento}

À Fundação de Amparo à Pesquisa do Estado de São Paulo (FAPESP) pelo apoio, sem o qual a pesquisa não seria possível. 


\section{Referências}

HAANDEL, A.C.V.; LUBBE, J.V.D. (2007) Handbook of biological wastewater treatment. Design and optimization of activated sludge systems. V. 1. Leidschendam: Quist.

HEM, L.J.; ØDEGAARD, H.; RUSTEN, B. (1994) Nitrification in a moving bed biofilm reactor. Water Resources (G.B.), n. 28, p. 1425-1433.

LESSEL, T.H. (1993) Upgrading and nitrification by submerged bio-film reactors - experiences from a large scale plant. In: International Conference Specializae on Biofilm Reactors, 2 Anais. Paris, p. 231-238.

MARAIS, G.V.R.; EKAMA, G.A. (1976) The activated sludge process Part I: steady state behaviour. Water SA, v. 2, n. 4, p. 164-200.

METCALF \& EDDY, Inc. (2003) Wastewater engineering: treatment and reuse, $4^{\mathrm{a}}$ ed. Nova York: Ed. McGraw-Hill.
MINEGATTI, D.V.O.; VOLSCHAN Jr., I.; JORDÃO, E.P. (2011) Comportamento e desempenho do processo reator biológico com leito móvel (MBBR) para a remoção da matéria orgânica e compostos nitrogenados. Revista AIDIS de Ingeniería y Ciencias Ambientales, v. 4/1, p. 12-26.

ØDEGAARD, H.; RUSTEN, B. (1993) Wastewater treatment with aerated submerged biological filters. Journal Water Pollution Control Federation, v. 56, n. 5, p. $424-431$.

RUSTEN, B.; HEM, L.; ØDEGAARD, H. (1995) Nitrification of municipal wastewater in moving-bed biofilm reactors. Water \& Environment Research, n. 67, p. 75-86.

WEF/ASCE/EWRI. (2009) Design of municipal wastewater treatment plants: WEF manual of practice no 8 and ASCE Manuals and reports on engineering practice v. 2, n. 76, 5. ed. Alexandria e Reston, Virginia: Ed. McGraw-Hill. 